\title{
Myogenin level tends to decrease in adult male cigarette smokers
}

\author{
Augustine C. Ihim*, Patrick O. Manafa*, Vincent T. Ekechukwu* Manafa I. Vera**, \\ Victor N. Chukwudi***, and Sabina O. Ogbuowelu*
}

\begin{tabular}{l} 
\\
\hline *Chemical Pathology Unit, \\
Department of Medical Laboratory \\
Science, Faculty of Health Sciences \\
and Technology, Nnamdi Azikiwe \\
University, Nnewi Campus, \\
Anambra State, Nigeria \\
**Pathology Department, East Kent \\
Hospital University Foundation \\
Trust, Kent \\
***Department of Medical \\
Laboratory Science, Faculty of Health \\
Sciences and Technology, Owerri, \\
Imo State, Nigeria \\
Correspondence: \\
Augustine C. Ihim, Ph.D. \\
Chemical Pathology Unit, \\
Department of Medical Laboratory \\
Science, Faculty of Health Sciences \\
and Technology, Nnamdi Azikiwe \\
University, P.M.B. 5025 Awka, \\
Anambra State, Nigeria \\
Email:ac.ihim@unizik.edu.ng \\
Phone +2348035985883 \\
ORCID ID : 0000-0001-9991-0714
\end{tabular}

Date of first submission, June 15, 2020

Date of final revised submission,

October 20, 2020

Date of acceptance, October 27, 2020

This open access article is distributed under a Creative Commons AttributionNon Commercial-Share Alike 4.0 International License

\begin{abstract}
BACKGROUND
The World Health Organization has warned that cigarette smoking is an avoidable risk factor for endothelial injury. Myogenin might play a role in muscle metabolism and energy utilization. Electrolytes and minerals are involved in most cellular activities. The objective of this study was to compare myogenin and electrolyte levels between adult male cigarette smokers (CS) and non-smokers (NS).
\end{abstract}

\section{METHODS}

A cross-sectional study was conducted involving 90 subjects, consisting of $55 \mathrm{CS}$ and $35 \mathrm{NS}$. The sandwich enzyme-linked immunosorbent assay was used to determine myogenin levels while the ion-selective electrode method was used to determine electrolyte levels. The levels of sodium, potassium, and chloride and the body mass index (BMI) were measured. Mann-Whitney and independent t-test were used to analyse the data.

\section{RESULTS}

The BMI of CS was significantly lower than that of NS $(p<0.05)$. The mean serum levels of sodium (145.23 \pm 1.87$)$, potassium $(4.00 \pm 0.31)$ and chloride $(103.95 \pm 1.60)$ were significantly higher in the CS than in the NS (these being $142.38 \pm 2.49,3.83 \pm 0.33$, and $101.48 \pm 2.08$, respectively) $(\mathrm{p}<0.05)$. Myogenin levels $(44.24 \pm 14.60 \mathrm{pg} / \mathrm{mL})$ tended to decrease in the CS group compared to the NS group $(59.66 \pm 61.73 \mathrm{pg} / \mathrm{mL})$, but the difference was statistically not significant $(\mathrm{p}=0.769)$.

\section{CONCLUSION}

The study demonstrated that higher concentrations of sodium, potassium and chloride with lower concentrations of myogenin in smokers may be associated with higher risk of skeletal muscle tissue injury probably due to the inability of the affected small blood vessels to transport electrolytes to tissues.

Keywords: Tobacco, myogenin, electrolyte, smokers

Cite this article as: Ihim AC, Manafa PO, Ekechukwu VT, Vera MI, Chukwudi VN, Ogbuowelu SO. Myogenin level tends to decrease in adult male cigarette smokers. Univ Med 2020;39:178-83. doi: 10.18051/UnivMed.2020.v39.178-183 


\section{INTRODUCTION}

Cigarette production involves a number of substances and materials other than just tobacco, paper and a filter. Tobacco additives include flavorings, enhancers, humectants, sugars, and ammonium compounds. ${ }^{(1)}$ Nicotine is an addictive substance in cigarettes which causes regular intake of the cigarette smoke that leads to health harms and death. Today, the uncountable negative effects of cigarette smoking are widely accepted. ${ }^{(2)}$ The rate of smoking is still rising in some parts of developing nations ${ }^{(3)}$ and close to half of cigarette smokers die of tobacco-related diseases and lose an average 14 years of life. ${ }^{(2)}$ Cigarette smoke contains about 7,000 chemical compounds, including not limited to cyanide, lead, nicotine, carbon monoxide, arsenic, formaldehyde, acrolein and other harmful substances and about 70 of these can lead to cancer. ${ }^{(4)}$ Smoking, a preventable risk factor for endothelial injury, is said to have become the global number two killer after hypertension. ${ }^{(5)}$ Cigarette use is the leading cause of preventable diseases, which could result in pathologies of most organs and tissues in the body, such as the kidneys and oral cavity ${ }^{(6)}$ Cigarette smoking also has great effect on systemic tissues such as skeletal muscle. ${ }^{(7)}$

These tissues are important in the day-today hormonal functions of the body and its metabolism, including electrolyte balance and myogenin sensitivity which shows the remarkable and harmful impact of smoking on metabolism of skeletal muscle and kidney homeostatic function. Cigarette smoke contains substances that can stimulate the breakdown of muscle protein and inhibit protein synthesis and this could lead to muscle dysfunction. ${ }^{(8)}$ Myogenin is a muscle-specific transcription factor which helps in the co-ordination of the development and repair of skeletal muscle..$^{(9)}$ Myogenin as a skeletal muscle biomarker can denote the presence of skeletal muscle dysfunction. Even though its role in adult skeletal muscle is still uncertain, previous studies suggest that myogenin has a vital role as a high-level transcriptional regulator that controls the energy balance between aerobic and anaerobic metabolism of the skeletal muscle of an adult. ${ }^{(10)}$ Electrolytes, which are substances that can conduct electric current, are located in the intracellular and extracellular fluid in the body with sodium being the major cation and chloride being the major anion in the extracellular fluid. Potassium is the major cation in the intracellular fluid. Electrolytes can dissociate in solution and play a major role in homeostasis. ${ }^{(11)}$ The serum electrolytes which include sodium, potassium, chloride and bicarbonate enable the body to maintain and regulate nerve function, water balance, acid-base balance and muscle function and these electrolytes can be increased or decreased in pathological conditions such as organ damage (e.g. of the kidneys) or diseased conditions which lead to imbalance of the serum electrolytes. ${ }^{(12)}$ Sodium and potassium are vital for nerve function and nerves have the function of signaling the muscle to contract and relax by passing electric impulses from the brain to the muscle tissues. During muscle relaxation, sodium levels are higher inside the muscle cells than outside. During contraction, which is initiated by a signal from the nerves, sodium flows into the cell while potassium flows out. ${ }^{(13)}$ Also research has shown the importance of calcium, magnesium and chloride in the contraction and relaxation of the skeletal muscles. ${ }^{(14,15)}$

Numerous studies have shown that smoking has a very harmful effect on the lungs with an indirect effect on the tissues of the muscles. A recent study shows that smoking decreases the number of small blood vessels that bring oxygen and nutrients to muscles in the legs. ${ }^{(16)}$ It was discovered that smoking makes the muscles weaker and thereby limits the ability of an individual to exercise and this was due to inflammation of the lungs and subsequent destruction by habitual smoking thereby limiting exercise. Recent findings suggest that cigarette smoke damages muscle cells directly by reducing the number of blood vessels in leg muscles which 
leads to oxygen reduction and reduced nutrient intake. This can have an effect on muscle metabolism and its level of activity. ${ }^{(16)}$

Myogenin is present in skeletal muscle and is essential to promote terminal differentiation of myocytes. It has been observed that longterm cigarette smoking significantly decreases myogenin expression in the gastrocnemius tissues of rats. ${ }^{(17)}$ Besides, salidroside mitigates skeletal muscle atrophy in rats with cigarette smoke-induced chronic obstructive pulmonary disease (COPD) by up-regulating myogenin and down-regulating myostatin expression. Electrolyte imbalance could greatly affect skeletal muscle function. Hypophosphatemia and hypokalemia are the most known causes of myopathy. ${ }^{(18)}$ A study in thirty smokers and thirty non-smokers as matched controls showed a significant increase in sodium level immediately after smoking and no significant change in potassium level in smokers. ${ }^{(19)}$ Another study involving 100 male smokers and 40 non-smokers showed a significant effect on the activity of liver enzyme, calcium, phosphate and iron levels in smokers compared to non-smokers but no significant effect on sodium, chloride and potassium levels in smokers. ${ }^{(20)}$ Previous studies have focused on the effect of smoking on expression of electrolytes and included myogenin as difference variable. The objective of the present study was to compare the levels of myogenin and electrolytes between adult male cigarette smokers and non-smokers.

\section{METHODS}

\section{Research design}

This cross-sectional study was designed to compare the levels of myogenin and electrolytes between adult male smokers and non-smokers. This study was carried out between January and August, 2019.

\section{Study subjects}

The sample size was calculated using G*Power software version 3.0.10 (Heinrich
Heine Universität Düsseldorf, Germany). Power analysis for difference between two independent means (groups) was conducted in $\mathrm{G}^{*}$ Power to determine a sufficient sample size using an alpha of 0.05 , a power of 0.80 and a medium effect size. Based on these, the calculated total sample size of 84 has a power of $80 \%$ to detect a difference of 0.50 at a significance level of 0.05 . A total of 90 participants within the age of 1865 years were recruited by convenience sampling for this study, comprising 55 smokers (test) and 35 non-smokers (control). The inclusion criterion was male CS and NS within the age range of 18-65 years. and the exclusion criterion was subjects with underlying disease such as diabetes mellitus, autoimmune disorders and skeletal muscle diseases. Participants for this study were recruited from Nnamdi Azikiwe University teaching hospital, restaurants and drinking pubs within Nnew Metropolis, Anambra State, Nigeria.

\section{Laboratory analysis}

Determination of the levels of electrolytes was based on a potentiometric method using ion selective electrodes ${ }^{(21)}$ while the evaluation of the levels of myogenin was based on the double antibody sandwich enzyme-linked immunosorbent assay (ELISA) using the Human Myogenin (MYOG) ELISA Kit-NP_002470.2 (catalog no. MBS765394, MyBiosource, San Diego (USA)) method according to the manufacturer's instructions, as described also in a previous protocol. $^{(22)}$

\section{Statistical analysis}

The IBM Statistical Package for Social Sciences (SPSS) version 21 was used for the statistical analysis. In order to decide whether to use parametric or non-parametric tests to calculate significance, the distribution of each group was tested for normality. Frequency, duration of cigarette smoking, myogenin, sodium, chloride, and bicarbonate levels were not normally distributed while weight, height, age, potassium and BMI were normally distributed. 
Table 1. Comparison of age and body mass index between of cigarette smokers and non- smokers

\begin{tabular}{lccc}
\hline \multicolumn{1}{c}{ Variable } & Smokers $(\mathbf{n}=\mathbf{5 5})$ & Non-smokers $(\mathbf{n}=\mathbf{3 5})$ & p-value \\
\hline Age $($ years $)$ & $34.70 \pm 9.51$ & $38.75 \pm 15.97$ & 0.630 \\
BMI $\left(\mathrm{kg} / \mathrm{m}^{2}\right)$ & $23.26 \pm 1.69$ & $23.92 \pm 1.61$ & $* 0.024$ \\
\hline
\end{tabular}

*Statistically significant at $\mathrm{p}<0.05$; independent $\mathrm{t}$ - test

The majority of the variables were non-normally distributed. The Mann-Whitney U. and independent-t test were used to subject all collected data to statistical analysis. Values were deemed significant at $\mathrm{p}<0.05$.

\section{Ethical approval}

The ethical approval for this research was obtained from Nnamdi Azikiwe University Teaching Hospital ethics committee with reference NAUTH/CS/66/VOL.12/46/2019/ 078 .

\section{RESULTS}

The mean body mass index $\left(\mathrm{kg} / \mathrm{m}^{2}\right)$ of CS (23.26 \pm 1.69$)$ compared with NS $(23.92 \pm 1.61)$ was significantly raised $(\mathrm{p}<0.05)$. However, mean age was not significantly different between CS and NS $(p=0.630)$ (Table 1$)$.

\section{DISCUSSION}

The significantly lower body mass index in smokers found in this study corroborated previous studies. ${ }^{(23-25)}$ It has been shown that smoking and nicotine reduce weight by raising the demand for body energy and suppressing appetite. ${ }^{(26)}$ Smoking has been linked to promoting some genetic variants thus causing low BMI value. ${ }^{(27)}$ The low BMI value is also attributed to a number of physiological mechanisms associated to the possible role of behavioral pattern common with cigarette smokers. One study (23) examined the relationships between sedentary behavior, smoking status, viz. current smokers, nonsmokers and former smokers and weight-related outcomes. Sedentary behavior was significantly higher among current smokers compared to nonsmokers and former smokers; former smokers had higher levels of sedentary behavior compared to never smokers. ${ }^{(23)}$ It was seen that at low levels of sedentary behavior, current smokers and never smokers did not have significant differences in BMI. However, at moderate and high levels of sedentary behavior, current smokers had a significantly lower BMI compared to non-smokers in those sedentary behavior categories. Previous research has demonstrated that nicotine affects the body by increasing its metabolism. ${ }^{(25)}$ Thus, nicotineinduced increase in metabolism could have been responsible for lower BMI among smokers. ${ }^{(23)}$ The significantly higher levels of serum sodium, potassium and chloride observed in the present study may be attributed to the effects of cigarette-smoking on small blood vessels leading to reduced blood flow to muscle tissues. The reduced blood flow could lead to reduced flow of electrolytes to the muscles, ${ }^{(16)}$ and could raise the levels of the electrolytes in the blood. The

Table 2. Comparison of myogenin and electrolyte levels between smokers and non-smokers

\begin{tabular}{lccc}
\hline Variable & Smokers $(\mathbf{n}=\mathbf{5 5})$ & Non-smokers $(\mathbf{n}=\mathbf{3 5})$ & p-value \\
\hline Myogenin $(\mathrm{pg} / \mathrm{mL})$ & $44.24 \pm 14.60$ & $59.66 \pm 61.73$ & $0.769^{\mathrm{a}}$ \\
Sodium $(\mathrm{mmol} / \mathrm{L})$ & $145.23 \pm 1.87$ & $142.38 \pm 2.49$ & $0.000^{* \mathrm{a}}$ \\
Potassium $(\mathrm{mmol} / \mathrm{L})$ & $4.00 \pm 0.31$ & $3.83 \pm 0.33$ & $0.118^{* \mathrm{~b}}$ \\
Chloride $(\mathrm{mmol} / \mathrm{L})$ & $103.95 \pm 1.60$ & $101.48 \pm 2.08$ & $0.000^{* \mathrm{a}}$ \\
Bicarbonate $(\mathrm{mmol} / \mathrm{L})$ & $22.40 \pm 1.88$ & $22.68 \pm 1.95$ & $0.615^{\mathrm{a}}$ \\
\hline
\end{tabular}

significant at $\mathrm{p}<0.05{ }^{\text {a }}$ Mann-Whitney test ${ }^{\mathrm{b}}$ Independent $\mathrm{t}$-test 
reduction in small blood vessels leads to reduced amounts of oxygen and nutrients they can receive. This can impact on muscle metabolism and activity levels, both of which are risk factors for many chronic diseases including diabetes and chronic obstructive pulmonary disease (COPD). ${ }^{(16)}$ Research has shown that with advancement in age of humans and animals, they are less able to regulate sodium and water retention, urine concentration and thirst compared to their younger counterparts. ${ }^{(28)} \mathrm{With}$ increase in duration of smoking, there could be increase in sedentary behaviors and also increased physiological effects of nicotine ${ }^{(29)}$ which could lead to an increase in body mass index. The lower values of serum myogenin seen in this study could be due to the presence of muscle stress caused by increase in age, frequency of smoking and duration of smoking. Smoking could damage the muscle cells directly and reduce the number of blood vessels in the leg muscles leading to tissue hypoxia. It is difficult to identify the causes of abnormal serum electrolytes in smokers and non-smokers due to the nature of study design which describes only what is happening at the present time. Further research is needed using a better design such as cohort study to evaluate the effect of smoking on myogenin and electrolyte levels.

\section{CONCLUSION}

The observed higher concentrations of sodium, potassium and chloride with lower concentrations of myogenin in smokers may be associated with higher risk of skeletal muscle tissue injury probably due to the inability of the affected small blood vessels to transport electrolytes to tissues. The risk is increased with age, duration of smoking and frequency of smoking.

\section{CONFLICTS OF INTEREST}

The authors declare that they have no conflicts of interest.

\section{AUTHORS’ CONTRIBUTIONS}

ACI, POM, VTE and VNC conceived and designed the research proposal.VTE, SOO and VNC performed sample collection, and experiments and ACI and VIM analyzed the data. Discussion was done by VIM while ACI, VIM and POM contributed to the final version of the manuscript. All authors have read and approved the final version.

\section{ACKNOWLEDGEMENTS}

The authors express their gratitude to the management and staff of Nnamdi Azikiwe University Teaching Hospital, Nnew, Anambra State for the permission to analyze the samples in their laboratory.

\section{REFERENCES}

1. Paumgartten FJR, Gomes-Carneiro RM, Xavier de Oliveira ACA. The impact of tobacco additives on cigarette smoke toxicity: a critical appraisal of tobacco industry studies. Cad. Saúde Pública 2017;33 Sup 3:e00132415. doi: 10.1590/0102311X00132415.

2. Di Cicco ME, Ragazzo V, Jacinto T. Mortality in relation to smoking: the British Doctors Study. Breathe 2016;12:275-6. DOI: 10.1183/20734735. 013416.

3. World Health Organization Western Pacific Region. Tobacco in the Western Pacific. Manila: World Health Organization Western Pacific Region;2019.

4. Csordas A, Bernhard D. The biology behind the atherothrombotic effects of cigarette smoke. Nat Rev Cardiol 2013;10:219-30. DOI: 10.1038/ nrcardio.2013.8.

5. Dwyer-Lindgren L, Mokdad AH, Srebotnjak T, Flaxman AD, Hansen GM, Murray CJ. Cigarette smoking prevalence in US Countries: 1996-2012. Popul Health Metr 2014;12:5. https://doi.org/ 10.1186/1478-7954-12-5.

6. Jamal A, Agaku IT, O'Connor E, King BA, Kenemer JB, Neff L. Current cigarette smoking among adults - United States, 2005-2013. Morb Mortal Wkly Rep 2014;63:1108-12.

7. Thatcher MO, Tippetts TS, Nelson MB, et al. Ceramides mediate cigarette smoke-induced metabolic disruption in mice. Am J Physiol 
Endocrinol Metab 2014;307:E919-E27. doi: 10.1152/ajpendo.00258.2014.

8. Rom O, Kaisari S, Aizenbud D, Reznick AZ. Identification of possible cigarette smoke constituents responsible for muscle catabolism. J Muscle Res Cell Motil 2012;33:199-208. doi: 10.1007/s10974-012-9299-4.

9. Hernández-Hernández JM, García-González EG, Brun CE, Rudnicki MA. The myogenic regulatory factors, determinants of muscle development, cell identity and regeneration. Semin Cell Dev Biol 2017;72:10-18. doi: 10.1016/j.semcdb.2017.11.010.

10. Flynn JM, Meadows E, Fiorotto M, Klein WH. Myogenin regulates exercise capacity and skeletal muscle metabolism in the adult mouse. PLoS ONE 2010;5:e13535. doi:10.1371/journal. pone.0013535.

11. Kaur GP, Fry RR, Chhikara N, , BaliA, Garg R.Fluid and electrolyte homeostasis: Facts based comprehensive study. Int J Med Health Res 2018; 4:128-32.

12. Pohl HR, Wheeler JS, Murray HE. Sodium and potassium in health and disease. In: Sigel A, Sigel $\mathrm{H}$, Sigel RKO, editors. Interrelations between metal ions and human diseases. Dordrecht (Netherlands): Springer Science \& Business Media; 2013.pp.29-47. DOI: 10.1007/978-94-0077500-8.

13. Palanikumar M, Radzyukevich TL, Javadi HH, et al. Phospholemman is not required for the acute stimulation of $\mathrm{Na}^{+}-\mathrm{K}^{+}$-ATPase $\alpha_{2}$-activity during skeletal muscle fatigue. Am J Physiol Cell Physiol 2015;309:C813-22. doi: 10.1152/ajpcell.00205.2015.

14. De Baaij JH, Hoenderop JG, Bindels RJ. Magnesium in man: implications for health and disease. Am J Physiol 2015;95:1-46. doi: 10.1152/ physrev.00012.2014.

15. Pedersen TH, Riisager A, de Paoli FV, Chen TY, Nielsen OB. Role of physiological ClC-1 Cl- ion channel regulation for the excitability and function of working skeletal muscle. J Gen Physiol 2016;147:291-308. doi: 10.1085/jgp.201611582.

16. Nogueira L, Trisko BM, Lima-Rosa FL, et al. Cigarette smoke directly impairs skeletal muscle function through capillary regression and altered myofiber calcium kinetics in mice. J Physiol 2018;596:2901-16. DOI: 10.1113/JP275888.

17. Zhang D, Cao L, Wang Z, et al. Salidroside mitigates skeletal muscle atrophy in rats with cigarette smoke-induced COPD by up-regulating myogenin and down-regulating myostatin expression. Biosci Rep 2019;39:BSR20190440. doi: 10.1042/BSR20190440.
18. Yeter HH. Endocrine myopathies: clinical review. Endocrinol Metab Synd 2015;4:178. doi:10.4172/ 2161-1017.1000178.

19. Emad-Aldin IO, Abdullah AD, Omer WH, Elimiri GM. Effect of cigarette smoking on blood sodium and potassium levels in Sudanese subjects. Int $\mathbf{J}$ Pharm Biol Sci 2011;2:75-9.

20. Dhahir NK, Noaman AA. Study effect of cigarette smoking on the liver functions and electrolyte. Iraqi J Sci 2017;58:211-5.

21. Albert V, Subramanian A, Rangarajan K, Pandey RM. Agreement of two different laboratory methods used to measure electrolytes. J Lab Physicians 2011;3:104-9.

22. Kohl TO, Ascoli CA. Immunometric doubleantibody sandwich enzyme-linked immunosorbent assay. Cold Spring Harb Protoc 2017.pdb.prot093724. doi: 10.1101/ pdb.prot093724.

23. Kaufman A, Augustson EM, Patrick H. Unraveling the relationship between smoking and weight: the role of sedentary behavior. J Obes 2012;2012: 735465. doi: 10.1155/2012/735465.

24. Watanabe T, Tsujino I, Konno S, et al. Association between smoking status and obesity in a nationwide survey of Japanese adults. PLoS ONE 2016;11:e0148926. doi:10.1371/journal.pone. 0148926.

25. Piirtola M, Jelenkovic A, Latvala A, et al. Association of current and former smoking with body mass index: a study of smoking discordant twin pairs from 21 twin cohorts. PLoS ONE 2018;13:e0200140. https://doi.org/10.1371/ journal.pone. 0200140 .

26. Audrain-McGovern J, Benowitz NL. Cigarette smoking, nicotine, and body weight. Clin Pharmacol Ther 2011;90:164-8. doi: 10.1038/ clpt.2011.105.

27. Locke AE, Kahali B, Berndt SI, et al. Genetic studies of body mass index yield new insights for obesity biology. Nature 2015; 518:197-206.

28. Ji H, Zheng W, Wu X, et al. Aging and related impairment of urine concentrating mechanisms correlates with dysregulation of adrenocortical angiotensin type 1 receptors in male Fischer rats. Am J Physiol Regul Integr Comp Physiol 2016;310:R513-21. doi: 10.1152/ajpregu.00131. 2015.

29. Nikoloutsou I, Vasileiou V, Litsiou E, et al. Smoking cessation changes basic metabolism, body weight, leptin and insulin levels, adipose tissue percentage, index of insulin resistance and index of insulin secretion. Tob Induced Dis 2014;12:A24. https://doi.org/10.1186/1617-9625-12-S1-A24. 